\title{
Interferon Is Superior to Direct Acting Antiviral Therapy in Tertiary Prevention of Early Recurrence of Hepatocellular Carcinoma
}

\author{
Wei Teng 1,2,3, Wen-Juei Jeng 1,2,3,4,*, Hwai-I Yang ${ }^{2,5}$, Wei-Ting Chen 1,3®D, Yi-Chung Hsieh ${ }^{1,3}$, \\ Chien-Hao Huang ${ }^{1,3}$, Chen-Chun Lin ${ }^{1,3}$, Chun-Yen Lin ${ }^{1,3, * \mathbb{C}}$, Shi-Ming Lin ${ }^{1,3,4}$ and \\ I-Shyan Sheen ${ }^{1,3}$ \\ 1 Department of Gastroenterology and Hepatology, Chang Gung Memorial Hospital, Linkou Medical Center, \\ Taoyuan City 333, Taiwan; b101090023@gmail.com (W.T.); weiting1972@gmail.com (W.-T.C.); \\ cutebuw@yahoo.com.tw (Y.-C.H.); huangchianhou@gmail.com (C.-H.H.); lincc53@gmail.com (C.-C.L.); \\ lsmpaicyto@gmail.com (S.-M.L.); happy95kevin@gmail.com (I.-S.S.) \\ 2 Institute of Clinical Medicine, National Yang-Ming University, Taipei 112, Taiwan; hwaii.yang@gmail.com \\ 3 College of Medicine, Chang Gung University, Taoyuan City 333, Taiwan \\ 4 School of Traditional Chinese Medicine, College of Medicine, Chang Gung University, \\ Taoyuan City 333, Taiwan \\ 5 Genomics Research Center, Academia Sinica, Taipei 115, Taiwan \\ * Correspondence: Rachel.jeng@gmail.com (W.-J.J.); chunyenlin@gmail.com (C.-Y.L.); \\ Tel.: +886-3-328-1200 (ext. 8120) (W.-J.J.)
}

Received: 19 November 2019; Accepted: 17 December 2019; Published: 19 December 2019

\begin{abstract}
The elimination of chronic hepatitis $\mathrm{C}$ infection $(\mathrm{CHC})$ by pegylated interferon plus ribavirin (Peg-IFN/RBV) decreases hepatocellular carcinoma (HCC) recurrence rate. However, the tertiary prevention of HCC recurrence by direct acting antiviral agents (DAA) remains controversial. This study aims to compare the tertiary prevention effect between DAA and Peg-IFN/RBV in CHC-HCC patients. Three hundred and one patients who received curative HCC treatment were retrospectively recruited. The recurrence incidence rate (IR) was compared among patients either receiving Peg-IFN/RBV or DAA regimen or untreated by three timeframes (I: from HCC treatment to antiviral therapy; II: during antiviral therapy; III: after antiviral therapy). The prevention effect between Peg-IFN/RBV and DAA were compared in frame II and III after propensity score matching (PSM) with age, tumor staging, HCC treatment modality, and cirrhotic status. Before PSM, the recurrence IRs in three arms were comparable in frame I, while being lower in the Peg-IFN/RBV and DAA arm compared to the untreated arm in frame II. In frame III, the tertiary prevention effect lasted in the Peg-IFN/RBV arm $(p<0.001)$, but diminished in the DAA arm $(p=0.135)$ compared to untreated patients. After PSM, the HCC recurrence IR was higher in the DAA arm than the Peg-IFN/RBV arm in frame II (2724 vs. 666 per $10^{4}$ person-years, log-rank $\left.p=0.042\right)$ and III (5259 vs. 3278 per $10^{4}$ person-years, log-rank $p=0.048)$. Preantiviral ALBI grade therapy is the only predictor for postantiviral therapy HCC recurrence. In conclusion, the tertiary prevention effect of HCC recurrence was not durable in DAA-treated patients, but persisted in Peg-IFN/RBV treatment patients.
\end{abstract}

Keywords: antiviral treatment; early recurrence; propensity score matching

\section{Introduction}

Hepatocellular carcinoma (HCC) is the fourth leading cause of cancer related deaths in the world [1]. Chronic viral hepatitis infection (e.g., HBV, HCV) accounts for nearly $80 \%$ etiology of HCC [2]. Successful eradication of chronic HCV infection with the pegylated interferon-based regimen 
(Peg-IFN) has proved to reduce the occurrence ("secondary prevention") [3] and recurrence of HCC ("tertiary prevention") [4-6]. However, only selected patients are treated by Peg-IFN-based therapy due to its side effect and contraindication in those with decompensated cirrhosis. The sustained virologic response (SVR) rate in cirrhotic patients is also not satisfactory, which can be as low as 38\% [7]. Recently, the discovery of direct acting antiviral agent (DAA) regimens overturns the obstacles encountered in Peg-IFN/RBV regimen, leading to nearly $100 \%$ SVR rate and applicable regardless of cirrhotic status $[8,9]$. However, a recent meta-analysis concluded that the HCC occurrence and recurrence rates were comparable between DAA- and IFN-treated patients regardless of the higher SVR rate of the DAA regimen [10]. Moreover, several reports with single-arm DAA-treated HCV-HCC patients declared abruptly increased HCC recurrence rate after antiviral treatment [11-14], while conflicting results have been reported in other studies comparing to the untreated [15-25] or IFN-treated groups [10,21,26-30]. Concerns have been raised about the benefit and the timing of adjuvant DAA-based therapy. Some of these studies consisted of an IFN-containing DAA regimen $[27,28]$ and did not adjust for baseline characteristics before comparison [26,30]. The definition of follow-up duration varies across these studies $[10,21,23-30]$ and may lead to inconsistent or conflicting comparison results [31]. We therefore conducted this nested case-control study, using propensity score matching (PSM) to adjust for the confounders, and with application of different follow-up time frames to investigate if the tertiary prevention effect is different between the DAA and PegIFN/RBV regimens in curative CHC-HCC patients.

\section{Results}

\subsection{Characteristics of the Peg-IFN/RBV, DAA, and Untreated Arms before Matching}

A total of $301 \mathrm{CHC}-\mathrm{HCC}$ patients that had received curative HCC treatment were analyzed. There were 56 patients treated with peginterferon $\alpha-2 \mathrm{a}$ (Pegasys) and 46 treated with peginterferon $\alpha-2 \mathrm{~b}$ (Peg-intron) in the IFN arm, while most patients $(n=32)$ received a sofosbuvir-based regimen in the DAA arm (Daclatasvir/Asunaprevir, $n=23$; Ombitasvir/paritaprevir/ritonavir, $n=20$; Elbasvir/Grazoprevir, $n=4)$, as seen in Figure 1.

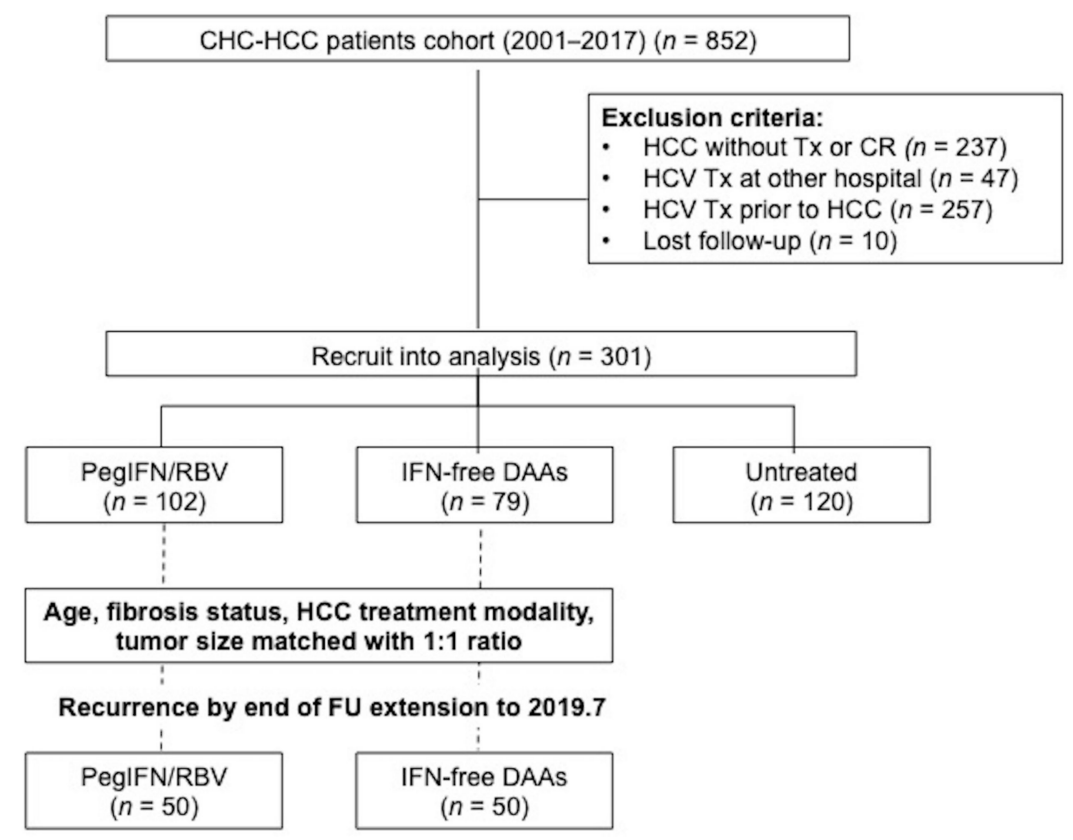

Figure 1. Flowchart of patient recruitment. Abbreviations: $C R$-complete response; DAA—direct-acting antiviral agents; HCC-hepatocellular carcinoma; HCV-hepatitis C virus infection; PegIFN/RBVPegylated interferon plus ribavirin; PSM-propensity scoring matching; Tx-treatment. 
At the time of HCC diagnosis, the untreated patients were older $(p<0.0001)$, had more Child-Pugh class B status $(p=0.0414)$, had larger tumor size $(p<0.0001)$, and none received surgical resection $(p<0.0001)$ than those in the Peg-IFN/RBV or DAA groups. Patients receiving the DAA regimen had more advanced fibrotic status, including higher FIB-4 score $(p<0.0001)$ and higher ALBI grade $(p=0.0060)$ than the Peg-IFN/RBV or untreated groups. The median follow-up duration from HCC complete response was the longest in the Peg-IFN/RBV arm (91.3 (3.4-224.8) months) followed by the DAA arm (53.4 (4.9-190.2) months) and the untreated arm (35.9 (3.8-100.8) months) $(p<0.0001)$, as seen in Supplementary Table S1.

At the start of antiviral therapy, the DAA arm was older $(p<0.0001)$, had more advanced fibrotic status $(p<0.0001)$, and more proportion of HCV genotype $1(p=0.0009)$ than the Peg-IFN/RBV group. The duration from HCC complete response to the start of antiviral therapy was comparable between two groups (median: Peg-IFN/RBV vs. DAA: $6.1(0.1-110.6)$ vs. $8.2(0.4-141.8)$ months, $p=0.5216)$. All treated patients were followed long enough for evaluating their SVR status. SVR rate was higher in the DAA group than the PegIFN/RBV group (96.1\% vs. $57.7 \%, p<0.0001)$. The follow-up duration from the start of antiviral therapy to last follow-up was much longer in the PegIFN/RBV arm than in the DAA arm (median: 72.5 (9.7-193.2) vs. $29.3(4-53.6)$ months, $p<0.0001)$ because DAA has been reimbursed by the Taiwan National Health Insurance Administration since December 2016, as seen in Supplementary Table S1.

\subsection{The Timing of Recurrence, Incidence Rate, and Recurrence Patterns between Different Arms before Matching}

During a median follow-up of 53.6 months from HCC treatment, 135 (44.9\%) patients had HCC recurrence and less than one-third $n=39,28.9 \%$ ) were found before the start of antiviral therapy. Fourteen patients encountered HCC recurrence during antiviral treatment, while the other 82 patients had HCC recurrence from the end of antiviral therapy (EOT) to two-year follow-up. Counting from the start of antiviral therapy, the disease-free interval (RFI) was much shorter in the DAA arm than that in the Peg-IFN/RBV arm (median: 12.9 (95\% CI: 6-19.7) vs. 24.8 (95\% CI: 7.8-41.7) months, $p<0.001$ ). The one- and two-year HCC recurrence rate was higher in the DAA arm than in the Peg-IFN/RBV arm $(48.1 \%, 58.4 \%$ vs. $20.6 \%, 45.4 \%$ respectively, Log-rank test, $p=0.002)$, as seen in Figure $2 \mathrm{~A}$. In the Peg-IFN/RBV arm, patients with and without SVR had comparable HCC recurrence rate $(51.8 \%$ vs. $51.2 \%, p=0.9560)$. In the DAA arm, although the HCC recurrence rate seems higher in SVR patients, it did not reach statistical significance because only one in the three non-SVR patients encountered recurrence $(60.8 \%$ vs. $33.3 \%, p=0.3414)$. There was no significant difference in the HCC recurrence between the sofosbuvir-based regimens and the others $(67.7 \%$ vs. $56.5 \%, p=0.3227)$.

During Frame I, the HCC recurrence incidence rate was comparable among the Peg-IFN/RBV, DAA, and untreated arms (Peg-IFN/RBV vs. DAA vs. untreated: 1409.7 vs. 1562.8 vs. 1660.0/10 4 person-years, overall $\log$-rank $p=0.564$ ), as seen in Table 1 and Supplementary Figure S1A. The recurrence patterns in Frame I were predominantly intrahepatic metastasis (71.8\%), comparable between the Peg-IFN/RBV and DAA arms $(64.7 \%$ vs. $77.3 \%, p=0.100)$, as seen in Supplementary Table S2. Seven patients with viable HCC at the start of antiviral therapy were excluded from entering Frames II and III. During Frame II, the untreated arm had a much higher incidence rate of HCC recurrence than the DAA and Peg-IFN/RBV arms, while the Peg-IFN/RBV arm had the lowest incidence rate of HCC recurrence (Peg-IFN/RBV vs. DAA vs. untreated: 1152.5 vs. 3126.2 vs. $6652.7 / 10^{4}$ person-years, overall log-rank $p<0.001)$, as seen in Table 1 and Supplementary Figure S1B. During Frame III, the incidence of HCC recurrence increased in both the Peg-IFN/RBV and DAA arms. However, the Peg-IFN/RBV arm still had the lowest incidence rate comparing to DAA and untreated arms and there was no difference between the DAA and untreated arms (Peg-IFN/RBV vs. DAA vs. untreated: 3851.0 vs. 5602.4 vs. $6734.6 / 10^{4}$ person-years, overall log-rank $p=0.186$ ), as seen in Table 1 and Supplementary Figure S1C. During Frames II and III, although an increased proportion of local recurrence was observed in the DAA arm compared to that in the DAA arm during Frame I (50\% vs. $22.7 \%)$, and slightly higher than that in Peg-IFN/RBV arm (50\% vs. $34 \%)$, no statistical significance was reached $(p=0.112)$. Six patients $(12 \%)$ in 
the Peg-IFN/RBV arm had distant HCC metastasis, while none had distant HCC metastasis in the DAA $\operatorname{arm}(p=0.015)$. The recurrent tumor number and maximum tumor size were comparable between the Peg-IFN/RBV and DAA arms ( $p=0.803, p=0.88$, respectively), as seen in Supplementary Table S2.

(A)

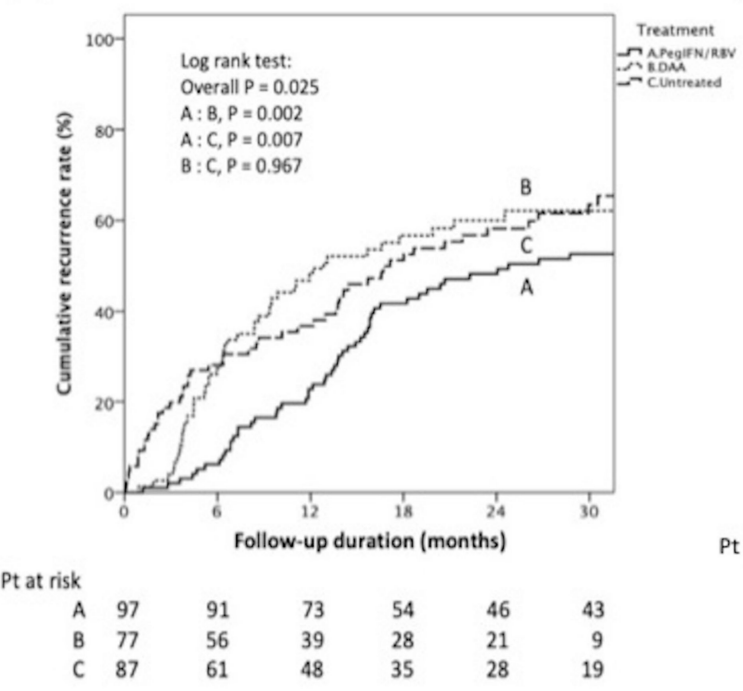

(B)

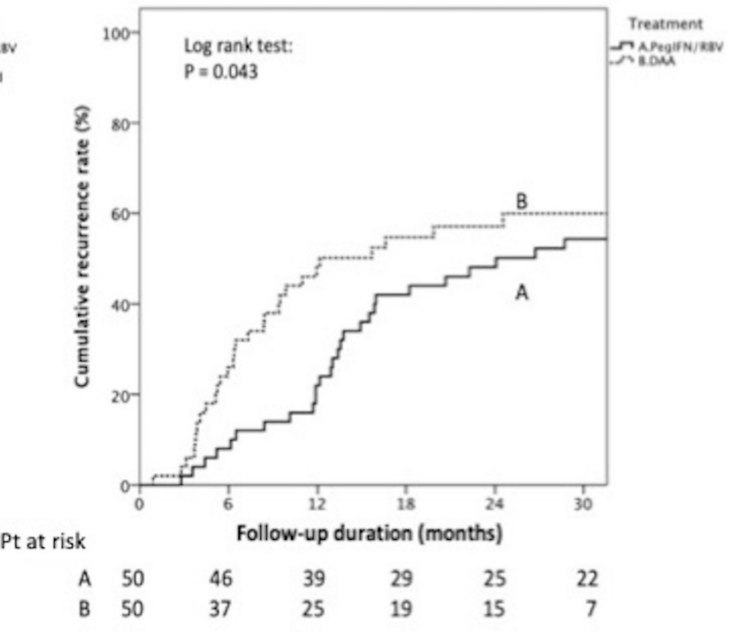

Figure 2. Kaplan-Meier curve showing cumulative HCC recurrence rate (A) among untreated, Peg-IFN/RBV, and DAA arms before PSM. From the start of HCV treatment, PegIFN/RBV group had the lowest one- and two-year HCC recurrence rate than DAA and untreated group (overall log-rank $p=0.025$ ) (B) comparison between Peg-IFN/RBV and DAA arms after PSM. From the start of HCV treatment, the PegIFN/RBV group had the lowest one- and two-year HCC recurrence rate compared to the DAA and untreated group (Log-rank $p=0.043)$.

\subsection{Tumor Recurrence after Propensity Score Matching between DAA and PegIFN/RBV Patients}

After propensity score matching of age, fibrosis status, HCC staging, and HCC treatment modality with a 1:1 ratio at the time of antiviral treatment commencement, fifty patients from each of the Peg-IFN/RBV and DAA arms were analyzed. The characteristics were comparable between these two groups, as seen in Table 2. The duration from HCC complete response to antiviral therapy was also comparable between the Peg-IFN/RBV and DAA arms (median: 6.1 vs. 8 months, $p=0.2398$ ). From the start of antiviral therapy, the Peg-IFN/RBV arm had longer RFI and lower one- and two-year cumulative HCC recurrence rates than the DAA arm (median RFI: 24.1 (95\%CI: 1.7-46.4) vs. 12.1 (95\%CI: 1.5-22.8), $p<0.001$; one- and two-year cumulative HCC recurrence rates: $22 \%, 48 \%$ vs. 48\%, 58\%, respectively, Log rank test, $p=0.043$ ), as seen in Figure 2B. In the DAA arm, there was no significant difference in HCC recurrence between the sofosbuvir-based regimens and the others $(65.0 \%$ vs. 56.7\%, $p=0.5562)$.

The incidence rate of HCC recurrence in Frame I was comparable between Peg-IFN/RBV and DAA arms (995.0 vs. $1017.1 / 10^{4}$ person-years, log-rank $\left.p=0.853\right)$, as seen in Supplementary Figure S1D. However, the incidence rate of HCC recurrence was higher in the DAA arm than that in the Peg-IFN/RBV arm in Frame II (2724.4 vs. 665.8/10 4 person-years, log-rank $p=0.042$ ), as seen in Supplementary Figure S1E, and Frame III (5259.4 vs. 3277.6/10 4 person-years, log-rank $p=0.048$ ), as seen in Supplementary Figure S1F and Table 1.

The one- and two-year cumulative HCC recurrence rates from commencement of antiviral therapy were comparable between the SVR and non-SVR arms $(37 \%, 49 \%$ vs. $30 \%, 64 \%, p=0.076)$. In all SVR patients, those treated with PegIFN/RBV had significantly longer RFI and lower one-year and two-year cumulative HCC recurrence rates than those treated with DAA (median RFI: 22.8 (2.8-176.4) vs. 10.3 (0.8-41.8) months, $p<0.001$; one- and two-year cumulative HCC recurrence rate: $16 \%, 32 \%$ vs. $48 \%, 56 \%$ respectively, Log rank test, $p=0.008$ ), as seen in Supplementary Figure S2. 
Table 1. The HCC recurrence rate in different time frames among the untreated, Peg-IFN/RBV, and DAA arms before and after PSM.

\begin{tabular}{|c|c|c|c|}
\hline Variables & $\begin{array}{c}\text { Frame I } \\
\text { End of Hepatoma Treatment to Initiation of HCV Treatment }\end{array}$ & $\begin{array}{c}\text { Frame II } \\
\text { During HCV Treatment }\end{array}$ & $\begin{array}{c}\text { Frame III } \\
\text { EOT to Two Years Post-EOT }\end{array}$ \\
\hline \multicolumn{4}{|c|}{ Before PSM } \\
\hline PegIFN/RBV & $1409.7 / 10,000$ person-years & $1152.5 / 10,000$ person-years & $3851.0 / 10,000$ person-years \\
\hline DAA & After the end of hepatoma treatment $<6$ months & After the end of hepatoma treatment 6-12 months & After the end of hepatoma treatment $12-36$ months \\
\hline \multirow[t]{2}{*}{ Untreated } & $1660.0 / 10,000$ person-years & $6652.7 / 10,000$ person-years & $6734.6 / 10,000$ person-years \\
\hline & $\begin{array}{c}\text { Frame I } \\
\text { End of hepatoma treatment to initiation of } \mathrm{HCV} \text { treatment }\end{array}$ & $\begin{array}{c}\text { Frame II } \\
\text { During HCV treatment }\end{array}$ & $\begin{array}{c}\text { Frame III } \\
\text { EOT to two years post-EOT }\end{array}$ \\
\hline \multicolumn{4}{|c|}{ After PSM } \\
\hline PegIFN/RBV & 995.0/10,000 person-years & $665.8 / 10,000$ person-years & $3277.6 / 10,000$ person-years \\
\hline DAA & 1017.1/10,000 person-years & $2724.4 / 10,000$ person-years & $5259.4 / 10,000$ person-years \\
\hline
\end{tabular}

Abbreviations: CR—complete response; DAA—direct acting antiviral agents; EOT—end of HCV treatment; HCC—hepatocellular carcinoma; HCV—hepatitis C virus; IFN—interferon; PSM—propensity score matching. 
Table 2. Comparison of patient characteristics between the Peg-IFN/RBV and DAA arms after PSM.

\begin{tabular}{|c|c|c|c|c|}
\hline Variables & Overall $(n=100)$ & PegIFN/RBV $(n=50)$ & IFN-Free DAAs $(n=50)$ & $p$-Value \\
\hline \multicolumn{5}{|l|}{ Time of HCC treatment } \\
\hline Age (years) $^{\dagger}$ & $63.8 \pm 8.0$ & $63.1 \pm 7.4$ & $64.5 \pm 8.6$ & 0.3847 \\
\hline Gender (male, \%) & $52(52.0)$ & $25(50.0)$ & 27 (54.0) & 0.8415 \\
\hline TNM stage I/II/III, $n(\%)$ & $71 / 26 / 3(71.0 / 26.0 / 3.0)$ & $37 / 12 / 1(74.0 / 24.0 / 2.0)$ & $34 / 14 / 2(68.0 / 28.0 / 4.0)$ & 0.7361 \\
\hline $\begin{array}{l}\text { HCC treatment, } n(\%) \\
\text { Resection/RFA/Others }\end{array}$ & $24 / 52 / 24(24.0 / 52.0 / 24.0)$ & $13 / 28 / 9(26.0 / 56.0 / 18.0)$ & $11 / 24 / 15(22.0 / 48.0 / 30.0)$ & 0.4337 \\
\hline Total bilirubin (mg/dL) & $0.8(0.3-2.9)$ & $0.8(0.4-2.8)$ & $0.8(0.3-2.9)$ & 0.7500 \\
\hline $\operatorname{ALT}(\mathrm{U} / \mathrm{L})$ & $72(15-372)$ & $73(15-372)$ & $72(19-193)$ & 0.8227 \\
\hline Albumin $(\mathrm{g} / \mathrm{dL})^{\dagger}$ & $3.83 \pm 0.49$ & $3.85 \pm 0.53$ & $3.80 \pm 0.45$ & 0.6095 \\
\hline $\operatorname{AFP}(\mathrm{ng} / \mathrm{mL})$ & $19(2-6260)$ & $18(3-4861)$ & $13(2-6260)$ & 0.3945 \\
\hline Platelet $\left(10^{3} / \mu \mathrm{L}\right)$ & $115(17-251)$ & $119(17-251)$ & $103(33-217)$ & 0.1052 \\
\hline ALBI grade I/II+III, $n(\%)$ & $42 / 58(42.0 / 58.0)$ & $22 / 28(44.0 / 56.0)$ & $20 / 30(40.0 / 60.0)$ & 0.9184 \\
\hline FIB- 4 & $5.17(1.14-22.3)$ & $5.17(1.14-19.5)$ & $5.17(2.16-22.3)$ & 0.2884 \\
\hline APRI & $1.97(0.30-11.7)$ & $1.97(0.30-11.7)$ & $1.95(0.52-10.6)$ & 0.6003 \\
\hline Tumor numbers, $n(\%)$ & $1(1-5)$ & $1(1-5)$ & $1(1-5)$ & 0.8131 \\
\hline Target lesion size $(\mathrm{cm})$ & $2.0(0.8-10.0)$ & $2.1(0.8-10.0)$ & $2.0(1.0-5.0)$ & 0.2272 \\
\hline \multicolumn{5}{|l|}{ Time of HCV treatment } \\
\hline Age (years) ${ }^{+}$ & $65.8 \pm 8.1$ & $64.9 \pm 7.5$ & $66.8 \pm 8.6$ & 0.2403 \\
\hline Total bilirubin (mg/dL) & $0.8(0.4-4.1)$ & $0.8(0.4-2.7)$ & $0.9(0.4-4.1)$ & 0.2214 \\
\hline $\operatorname{ALT}(\mathrm{U} / \mathrm{L})$ & $86(16-300)$ & $99(16-300)$ & $84(21-198)$ & 0.1329 \\
\hline $\operatorname{Albumin}(\mathrm{g} / \mathrm{dL})^{\dagger}$ & $3.95 \pm 0.51$ & $3.91 \pm 0.52$ & $4.03 \pm 0.49$ & 0.1972 \\
\hline $\operatorname{AFP}(\mathrm{ng} / \mathrm{mL})$ & $14(2-317)$ & $15(3-178)$ & $11(2-317)$ & 0.1242 \\
\hline Platelet $\left(10^{3} / \mu \mathrm{L}\right)$ & $114(31-251)$ & $114(57-251)$ & $116(31-233)$ & 0.5648 \\
\hline ALBI grade I/II+III, n (\%) & $57 / 43(57.0 / 43.0)$ & $25 / 25(50.0 / 50.0)$ & $32 / 18(64.0 / 36.0)$ & 0.1558 \\
\hline FIB- 4 & $5.63(0.97-26.1)$ & $6.29(0.97-18.2)$ & $5.32(1.39-26.1)$ & 0.8550 \\
\hline APRI & $2.44(0.30-16.0)$ & $2.79(0.30-16.0)$ & $2.00(0.45-12.4)$ & 0.2868 \\
\hline Genotype $1 / 2, n(\%)$ & $75 / 25(75.0 / 25.0)$ & $31 / 19(62.0 / 38.0)$ & $44 / 6(88.0 / 12.0)$ & 0.0050 \\
\hline SVR, $n(\%)$ & $73(71.1)$ & $25(50.0)$ & $48(96.0)$ & $<0.0001$ \\
\hline Time to HCV treatment (months) & $7.2(0.1-141.8)$ & $6.1(0.1-110.6)$ & $8.0(0.6-141.8)$ & 0.2398 \\
\hline $\mathrm{F} / \mathrm{u}$ since $\mathrm{HCV}$ treatment (months) & $40.1(11.7-184.1)$ & $74.7(20.7-184.1)$ & $29.6(11.7-53.6)$ & $<0.0001$ \\
\hline
\end{tabular}

${ }^{+}$Demonstrated as mean \pm standard deviation. Abbreviations: AFP—alpha-fetoprotein; ALBI—albumin-bilirubin; ALT—alanine aminotransferase; APRI—AST to platelet ratio index; CR—complete response; CTP—Child-Turcotte-Pugh; DAA—direct acting antiviral agents; FIB-4—-fibrosis-4; F/u—follow-up; HCC—hepatocellular carcinoma; HCV-hepatitis C virus; PegIFN/RBV— pegylated interferon plus ribavirin; $n$, number; RFA—radiofrequency ablation; SVR—sustained virologic response. 


\subsection{Risk Factors for HCC Recurrence}

Before PSM, the only predictor for postantiviral therapy HCC recurrence in Peg-IFN/RBV patients was recurrence HCC history prior to antiviral therapy (HR: 2.584 (95\% CI: 1.274-5.243), $p=0.0094$ ). For the 56 SVR patients in the Peg-IFN/RBV arm, no predictors for HCC recurrence were found, and HCC recurrence history prior to antiviral therapy [HR: 4.210 (95\% CI: 1.307-13.56), $p=0.0167$ ] was the only predictor for HCC recurrence in non-SVR patients in the Peg-IFN/RBV arm. In DAA-treated patients, ALBI grade II/III (vs. I: aHR: 2.374 (95\% CI: 1.310-4.301), $p=0.0041)$ is an independent predictor for HCC recurrence. However, the HCV genotype's impact on HCC recurrence was only shown in the DAA group (genotype 2 vs. 1: aHR: 2.828 (95\% CI: 1.352-5.913), $p=0.0064$ ), but not in IFN therapy, as seen in Supplementary Table S3.

After PSM, 53 HCC recurrent patients were compared to the other 47 nonrecurrence patients. Higher serum total bilirubin level, lower albumin level, higher AFP level, lower platelet count, higher ALBI grade, higher FIB-4, and shorter time to HCV treatment were noted in the recurrent group, as seen in Supplementary Table S4. The one- and two-year cumulative HCC recurrence rates, independent predictors for HCC recurrence, were analyzed by Cox regression, and were higher during Frame I for pre-HCC treatment ALBI grade (II/III vs. I: adjusted HR: $2.02(1.03-3.96), p=0.04)$ and HCC treatment modality (other curative treatment vs. surgical resection: aHR: 7.97 (1.04-61.35), $p=0.046$ ). During frame II, antiviral therapy with DAA was the only predictor for HCC recurrence (DAA vs. Peg-IFN/RBV: aHR: $3.40(1.60-19.37), p=0.039)$. During frame III, pre-HCV ALBI grade at the start of antiviral therapy (II/III vs. I, aHR: $2.22(1.25-3.93), p=0.006)$ was the only independent predictor for HCC recurrence, while the duration from HCC treatment to antiviral treatment did not reached statistical significance by multivariate Cox regression analysis ( $>8$ vs. $\leq 8$ months: aHR: 0.65 (0.36-1.16), $p=0.144)$, as seen in Table 3. From the EOT, ALBI I had longer RFI and lower one- and two-year cumulative HCC recurrence rate than ALBI II/III (median RFI: 39.5 vs. 13.7 months; one- and two-year cumulative HCC recurrence rate: $32 \%, 39 \%$ vs. $40 \%, 70 \%$ respectively, Log rank test, $p=0.014$ ). 
Table 3. Independent predictors for HCC recurrence in different time frames after PSM.

\begin{tabular}{|c|c|c|c|c|c|c|c|c|c|}
\hline Variables & & All & Recurrence & Crude HR & $95 \% \mathrm{CI}$ & $p$-Value & Adjusted HR & $95 \%$ CI & $p$-Value \\
\hline \multicolumn{10}{|c|}{ Frame 1: End of hepatoma treatment to initiation of HCV treatment } \\
\hline \multirow{2}{*}{ HCC Tx modality } & Resection & 24 & 1 & Referent & & & Referent & & \\
\hline & Others & 76 & 15 & 8.510 & $1.117-64.83$ & 0.039 & 7.968 & $1.035-61.35$ & 0.046 \\
\hline \multirow{2}{*}{ TNM stage } & I & 71 & 12 & Referent & & & & & \\
\hline & $\mathrm{II} / \mathrm{III}$ & 29 & 4 & 1.078 & $0.340-3.422$ & 0.898 & & & \\
\hline \multirow{2}{*}{ Pre-HCC AFP } & $\leq 20$ & 55 & 8 & Referent & & & & & \\
\hline & $>20$ & 45 & 8 & 1.614 & $0.600-4.338$ & 0.343 & & & \\
\hline \multirow{2}{*}{ Pre-HCC ALBI grade } & I & 42 & 6 & Referent & & & Referent & & \\
\hline & $\mathrm{II} / \mathrm{III}$ & 58 & 10 & 1.755 & $1.148-4.857$ & 0.041 & 2.020 & $1.031-3.956$ & 0.040 \\
\hline \multirow{2}{*}{$\mathrm{HCV}$ treatment } & IFN & 50 & 6 & Referent & & & & & \\
\hline & DAA & 50 & 10 & 1.100 & $0.399-3.033$ & 0.853 & & & \\
\hline \multicolumn{10}{|c|}{ Frame 2: During HCV treatment } \\
\hline \multirow{2}{*}{ HCC Tx modality } & Resection & 24 & 2 & Referent & & & & & \\
\hline & Others & 76 & 4 & 0.748 & $0.136-4.102$ & 0.738 & & & \\
\hline \multirow{2}{*}{ TNM stage } & I & 71 & 4 & Referent & & & & & \\
\hline & $\mathrm{II} / \mathrm{III}$ & 29 & 2 & 1.470 & $0.268-8.060$ & 0.657 & & & \\
\hline \multirow[b]{2}{*}{ Pre-HCV AFP } & $\leq 20$ & 61 & 5 & Referent & & & & & \\
\hline & $>20$ & 39 & 1 & 0.284 & $0.033-2.437$ & 0.251 & & & \\
\hline \multirow{2}{*}{ Pre-HCV ALBI grade } & I & 57 & 4 & Referent & & & & & \\
\hline & II/III & 43 & 2 & 0.645 & $0.118-3.522$ & 0.612 & & & \\
\hline \multirow{2}{*}{ Time to HCV Tx } & $\leq 8$ months & 53 & 2 & Referent & & & & & \\
\hline & $>8$ months & 47 & 4 & 2.531 & $0.463-13.84$ & 0.284 & & & \\
\hline \multirow{2}{*}{$\mathrm{HCV}$ treatment } & IFN & 50 & 2 & Referent & & & & & \\
\hline & DAA & 50 & 4 & 3.397 & $1.596-19.37$ & 0.039 & & & \\
\hline \multicolumn{10}{|c|}{ Frame 3: EOT to two years post-EOT } \\
\hline \multirow{2}{*}{ HCC Tx modality } & Resection & 22 & 8 & Referent & & & & & \\
\hline & Others & 72 & 39 & 1.700 & $0.826-3.501$ & 0.150 & & & \\
\hline \multirow{2}{*}{ TNM stage } & I & 67 & 31 & Referent & & & & & \\
\hline & $\mathrm{II} / \mathrm{III}$ & 27 & 16 & 1.571 & $0.881-2.802$ & 0.126 & & & \\
\hline \multirow{2}{*}{ Pre-HCV AFP } & $\leqq 20$ & 56 & 23 & Referent & & & & & \\
\hline & $>20$ & 38 & 24 & 1.614 & $0.926-2.814$ & 0.091 & & & \\
\hline \multirow{2}{*}{ Pre-HCV ALBI grade } & I & 53 & 20 & Referent & & & Referent & & \\
\hline & $\mathrm{II} / \mathrm{III}$ & 41 & 27 & 2.401 & $1.366-4.219$ & 0.002 & 2.217 & $1.250-3.931$ & 0.006 \\
\hline \multirow[b]{2}{*}{ Time to HCV Tx } & $>8$ months & 43 & 16 & Referent & & & Referent & & \\
\hline & $\leq 8$ months & 51 & 31 & 1.792 & $1.005-3.195$ & 0.048 & 1.550 & $0.861-2.793$ & 0.144 \\
\hline \multirow{2}{*}{$\mathrm{HCV}$ treatment } & IFN & 48 & 23 & Referent & & & & & \\
\hline & DAA & 46 & 24 & 1.239 & $0.707-2.170$ & 0.453 & & & \\
\hline
\end{tabular}

Abbreviations: ALBI—albumin-bilirubin grade; DAA—direct acting antiviral agents; EOT—end of HCV treatment; HCC—hepatocellular carcinoma; HCV—hepatitis C virus; IFN-interferon; Tx-treatment. 


\section{Discussion}

HCC recurrence in chronic hepatitis C patients was highly associated with viremia [4]. Tertiary prevention by IFN-based therapy has been proved to reduce tumor recurrence and prolong survival in postsurgical resection HCC patients $[4,32,33]$. However, conflicting reports have shown uncertainty of the tertiary prevention effects of DAA treatment in HCC recurrence prevention [11,12,15,27,34-36]. These inconsistent results might come from a selection bias, since patients eligible for IFN-based therapy were younger and with better liver reserve, which are protective factors for HCC development, than those treated with the DAA regimen $[37,38]$. In addition, the time-lag bias, i.e., different time frames applied for recurrence analysis, as seen in Table 3, may lead to discrepant result interpretation. When the follow-up period begins from HCC treatment, it consists of a considerable duration prior to the start of antiviral treatment and counts the period lacking antiviral agents, leading to possible underestimation $[23,24,26,28-30]$. Furthermore, two of these studies [26,30] firstly included untreated patients as a control group and compared it to IFN-based and DAA arms. However, not only was the follow-up duration in the DAA arm too short (1.3 years in Minami et al. [26] and 1.5 years in Petta et al. [30]), but there were also significant baseline characteristic differences, including age and tumor burden, among the three groups that could further weaken the power of the conclusions that were made. Therefore, it is more logical and reasonable to adjust for potential confounders contributing to recurrence and to begin follow-up from the start of anti-HCV treatment when discussing the tertiary prevention effect of HCC recurrence by different antiviral therapies. There was only one study, conducted by Kinoshita et al. [27], using this rationale to compare the tertiary prevention effect between IFN-based and DAA therapies.

The strength of our study is that the median follow-up duration from the start of antiviral therapy was longer than two years in the DAA arm (median: 29.3 months), reflecting the tertiary prevention effect of early HCC recurrence, defined as recurrence events within two years post-HCC treatment [39] by the DAA regimen. The use of propensity score matching to stratify the differences between the Peg-IFN/RBV and DAA arms could avoid confounding factors potentially contributing to recurrence. Another strength of this study is using the time-varying exposure of different time frames, including from HCC treatment to the start of antiviral treatment (Frame I), the period of antiviral treatment (Frame II), and from EOT to two years post-EOT (Frame III). In Frames II and III, during and after antiviral therapy, the incidence rate of HCC recurrence was significantly lower in patients treated with Peg-IFN/RBV than in the DAA group prior to and after PSM. The tertiary prevention effect of DAA was momentary during antiviral therapy (Frame II) and diminished after the end of treatment, as seen in Supplementary Figure S1B,E. The HCC recurrence rate in the DAA treated arm was not higher than the untreated arm (DAA vs. untreated: 5602.4 vs. $6734.6 / 10^{4}$ person-years, log-rank $p=0.135$ ), echoing recent studies' findings [23-25]. In contrast, the tertiary prevention effect of the Peg-IFN/RBV regimen was sustained throughout the antiviral therapy and even after EOT, showing a significantly lower recurrence rate than the untreated and DAA arms, as seen in Table 1, Supplementary Figure S1C,F. This finding was in conflict with the study by Kinoshita et al. [27], which reported no significant difference of tumor recurrence between IFN and DAA groups after matching (2 years: $70 \%$ vs. $76 \%, p=0.68)$. The possible reason is that their study recruited a mixed population of patients receiving interferon plus ribavirin +/- DAA, interferon, and pegylated-interferon in the interferon arm, explaining the much lower SVR rate (36.5\%) in their study than in ours (57.7\%), which only consisted of patients treated with Peg-IFN plus ribavirin. The other possibility may that all their HCC patients were treated with RFA and half of the patients received more than two times the treatment before antiviral therapy, while ours consisted of surgical resection, explaining the much higher two-year recurrence rate in that study than in ours (DAA, IFN: $76 \%, 70 \%$ in Kinoshita et al [27]. vs. $58 \%, 48 \%$ in the current study). This also explains why their one-year HCC recurrence rate in the IFN-containing group was much higher than that in previous studies reported from Japan (one-year: $26 \%-35 \%$ vs. $0 \%-9.5 \%)[40,41]$. Another important difference between Kinoshita et al.'s study and ours is that their median follow-up duration in the DAA arm was much shorter than that in the current study (1.8 vs. 2.5 years) [27], as seen in Table 4. 
Table 4. Summary of currently available studies comparing DAA tertiary prevention effects with untreated or IFN arms.

\begin{tabular}{|c|c|c|c|c|c|c|c|c|c|c|c|}
\hline \multirow{2}{*}{ Source } & \multirow{2}{*}{ Year } & \multicolumn{3}{|c|}{ HCC Patients No. } & \multirow{2}{*}{ HCC Tx } & \multicolumn{3}{|c|}{ HCC Recurrence Rate } & \multirow{2}{*}{$\begin{array}{c}\mathrm{F} / \mathrm{u} \\
\text { Initiation }\end{array}$} & \multirow{2}{*}{ Median f/u Duration } & \multirow{2}{*}{$p$-Value } \\
\hline & & IFN & DAA & Untreated & & IFN & DAA & Untreated & & & \\
\hline Minami [26] & 2016 & 38 & 27 & 861 & RFA & $\begin{array}{r}1 \text { year: } 26.3 \% \\
2 \text { years: } 52.9 \%\end{array}$ & $\begin{array}{l}1 \text { year: } 21.1 \% \\
2 \text { years: } 29.8 \%\end{array}$ & $\begin{array}{l}1 \text { year: } 30.5 \% \\
2 \text { years: } 61.0 \%\end{array}$ & HCC Tx & $\begin{array}{c}\text { IFN: } 3.0 \text { years } \\
\text { DAA: } 1.3 \text { years } \\
\text { Untreated: } 3.0 \text { years }\end{array}$ & 0.10 \\
\hline Nagata $[28] *(\mathrm{PSM})$ & 2017 & 22 & 22 & - & $\begin{array}{l}\text { Resection } \\
\text { RFA }\end{array}$ & 5 years: $54.2 \%$ & 5 years: $45.1 \%$ & - & HCC Tx & $\begin{array}{l}\text { IFN: } 6.2 \text { years } \\
\text { DAA: } 2.3 \text { years }\end{array}$ & 0.54 \\
\hline Petta [30] & 2017 & 57 & 58 & 328 & $\begin{array}{l}\text { Resection } \\
\text { RFA }\end{array}$ & 5 years: $41.1 \%$ & 5 years: $39.1 \%$ & 5 years: $64.5 \%$ & HCC Tx & $\begin{array}{l}\text { IFN: } 2.8 \text { years } \\
\text { DAA: } 1.5 \text { years } \\
\text { Untreated: } 1.4 \text { years }\end{array}$ & 0.49 \\
\hline Kinoshita [27] * (PSM) & 2018 & 61 & 61 & - & RFA & $\begin{array}{l}1 \text { year: } 46 \% \\
2 \text { years: } 70 \%\end{array}$ & $\begin{array}{l}1 \text { year: } 51 \% \\
2 \text { years: } 76 \%\end{array}$ & - & HCV Tx & $\begin{array}{l}\text { IFN: } 7.2 \text { years } \\
\text { DAA: } 1.8 \text { years }\end{array}$ & 0.68 \\
\hline Nagaoki [29] (PSM) & 2018 & 32 & 32 & - & $\begin{array}{l}\text { Resection } \\
\text { RFA } \\
\text { SBRT } \\
\end{array}$ & $\begin{array}{c}1 \text { year: } 0 \% \\
3 \text { years: } 34 \%\end{array}$ & $\begin{array}{c}1 \text { year: } 5 \% \\
3 \text { years: } 26 \%\end{array}$ & - & HCC Tx & $\begin{array}{l}\text { IFN: } 5.3 \text { years } \\
\text { DAA: } 2.8 \text { years }\end{array}$ & 0.36 \\
\hline Huang [23] (IPTW) & 2018 & - & 62 & 87 & $\begin{array}{c}\text { Resection } \\
\text { RFA } \\
\text { SBRT } \\
\text { TACE }\end{array}$ & & 1 year: $47 \%$ & 1 year: $49.8 \%$ & HCC Tx & $\begin{array}{l}\text { DAA: } 2.6 \text { years } \\
\text { Untreated: } 1.8 \text { years }\end{array}$ & 0.93 \\
\hline Singal [24] (PSM) & 2019 & - & 304 & 489 & $\begin{array}{c}\text { Resection } \\
\text { RFA } \\
\text { TACE } \\
\text { TARE } \\
\text { SBRT }\end{array}$ & - & aHR: $0.91,95$ & oCI: 0.69-1.19 & HCC Tx & Overall: 0.9 years & $>0.05$ \\
\hline Cabibbo [25] (PSM/IPTW) & 2019 & - & 102 & 102 & $\begin{array}{l}\text { Resection } \\
\text { RFA }\end{array}$ & - & $\begin{array}{r}1 \text { year: } 15 \% \\
2 \text { years: } 27 \% \\
\end{array}$ & $\begin{array}{r}1 \text { year: } 20 \% \\
2 \text { years: } 40 \% \\
\end{array}$ & HCV Tx & $\begin{array}{c}\text { DAA: } 1.8 \text { years } \\
\text { Untreated: } 1.5 \text { years }\end{array}$ & 0.15 \\
\hline Current study (PSM) & 2019 & 50 & 50 & - & $\begin{array}{c}\text { Resection } \\
\text { RFA } \\
\text { TACE } \\
\text { Proton }\end{array}$ & $\begin{array}{r}1 \text { year: } 22 \% \\
2 \text { years: } 48 \%\end{array}$ & $\begin{array}{l}1 \text { year: } 48 \% \\
2 \text { years: } 58 \%\end{array}$ & - & HCV Tx & $\begin{array}{l}\text { IFN: } 6.2 \text { years } \\
\text { DAA: } 2.5 \text { years }\end{array}$ & 0.04 \\
\hline
\end{tabular}

carcinoma; IFN—interferon; IPTW—inverse probability of treatment weighting; PSM—propensity score matching; RFA—radiofrequency ablation; SBRT—-stereotactic body radiation therapy; TACE-transarterial chemoembolization. 
The ALBI score, derived from a regression model of albumin and bilirubin values, has been proposed as an objective grading system to evaluate the functional liver reserve in patients with cirrhosis or HCC. It has been widely validated for prediction of treatment outcome in patients with different HCC staging and treatment modalities [42-45]. Poor liver function, assessed by the ALBI grade, is associated with higher incidence of tumor recurrence [46,47]. In this study, patients with advanced liver fibrosis had higher risk for postantiviral treatment HCC recurrence. Patients of ALBI grade I had a significantly longer RFS rate and lower cumulative recurrence rate than their counterparts. Thus, patients with advanced fibrosis, even with SVR status, still require continued HCC surveillance.

The possible mechanism for the temporary protective effect by DAA compared to the durable effect of Peg-IFN/RBV therapy may due to the different immunological changes after different antiviral treatments. Recent studies showed the loss of intrahepatic immune activation by IFN $\alpha$ after DAA therapy due to the decreased levels of chemokine C-X-C motif ligand 10 (CXCL10), CXCL11, and a rapid decrease in NK cell activation and a normalization of NK cell cytotoxic effector functions [48], leading to ineffective surveillance of neoplastic clones. Another possible explanation is the epigenetic changes that induce H3K27ac modifications by chronic hepatitis $\mathrm{C}$ infection, associated with increased HCC risk, which persists even after HCV cure by DAA therapy [49].

There are several limitations in this study: First, the sample size was reduced after propensity score matching and increased censored cases in the DAA-treated arm two years after the end of HCV treatment were noted. Therefore, this study focused on early recurrence ( $<2$ years), and the impact of antiviral therapy on late recurrence ( $>2$ years) cannot be investigated in current setting; Second, TACE was used in nearly one-quarter of enrolled patients, which remains disputable as a curative treatment modality, although complete response has been documented in certain groups.

In conclusion, both IFN and DAA had different durabilities in their tertiary prevention effect for HCC recurrence in CHC-HCC patients after curative HCC treatment. The Peg-IFN/RBV regimen had a much better and more durable preventive effect than the temporary effect of DAA therapy. Close surveillance for detection of HCC recurrence is mandatory in curative HCC patients choosing DAA as a tertiary prevention regimen.

\section{Materials and Methods}

\subsection{Patient Recruitment}

Chronic hepatitis $\mathrm{C}$ patients with curative HCC status achieved by resection, radiofrequency ablation (RFA), transarterial chemoembolization (TACE), and/or proton therapy between January 2001 and December 2017 in Chang Gung Memorial Hospital, Linkou branch treated with antiviral agents were retrospectively recruited. Patients who received antiviral therapy and reached SVR before HCC treatment were excluded. Demographic features, including age, gender, fibrosis status, HCC status, HCV genotype, HCV viral load, and HCC treatment modality, were recorded at of the time of HCC diagnosis, HCV treatment initiation, and end of antiviral treatment. All subjects gave their informed consent to receive HCC treatment, and this retrospective study was approved by the Institutional Review Board committee in Linkou Chang Gung Memorial Hospital (201701340B0C501).

\subsection{Diagnosis of Hepatocellular Carcinoma and Follow-Up Protocol}

HCC was diagnosed with hyperattenuation in the arterial phase and washout in the late phase [50] by multiphasic, contrast-enhanced imaging (computed tomography (CT)/magnetic resonance imaging (MRI) scans) and/or histology according to European Association for the Study of the Liver/European Organization for Research and Treatment of Cancer (EASL/EORTC) diagnostic guidelines [51]. CT/MRI scans were performed approximately one month after HCC treatment to determine complete tumor response and before the initiation of antiviral therapies to confirm the absence of viable HCC nodules. Complete tumor response was defined as the absence of residual tumor or complete necrosis, and the images obtained before 2010 were reinterpreted by a radiologist according to the modified Response 
Evaluation Criteria in Solid Tumors (mRECIST) [52]. We monitored HCC recurrence by dynamic CT or MRI every 3-4 months for the first two years, which was then extended to six month intervals thereafter, and measurement of serum alpha-fetoprotein (AFP) levels was incorporated. HCC recurrence was diagnosed using the same criteria as applied to the diagnosis of HCC.

\subsection{Antiviral Regimens for HCV Eradication}

The PegIFN/RBV regimen composed of peginterferon $\alpha-2 \mathrm{a}(180 \mathrm{mg} /$ week) or peginterferon $\alpha-2 \mathrm{~b}$ $(1.5 \mathrm{mg} / \mathrm{kg} /$ week) subcutaneously plus weight-based ribavirin $(1000 \mathrm{mg} /$ day for weight $<75 \mathrm{~kg}$ and $1200 \mathrm{mg} /$ day for weight $>75 \mathrm{~kg}$ ). Undetectable serum HCV-RNA at 24 weeks after the cessation of treatment was SVR. Patients received DAA therapy according to their HCV genotype and the severity of liver disease, in accordance with the current guidelines [53]. Undetectable HCV RNA at 12 weeks after the end of HCV treatment (EOT) defined as SVR. Those who failed to achieve SVR were defined as treatment failures (TF).

\subsection{Laboratory Methods}

Hemogram and liver biochemistry tests were performed using automated techniques at the clinical pathology laboratories of the hospital. Commercial kits were used for serum anti-HCV assay (Abbott Laboratories, North Chicago, IL, USA) and AFP level (Abbott Laboratories, lower limit of detection: $2 \mathrm{ng} / \mathrm{mL}$ ). The HCV-RNA levels in this study were measured using a commercial quantitative polymerase chain reaction (PCR) assay, COBAS TaqMan HCV Test (TaqMan HCV; Roche Molecular Systems Inc., Branchburg, NJ, USA, lower limit of detection: $15 \mathrm{IU} / \mathrm{mL}$ ). The HCV genotype was determined using a genotype-specific probe-based assay in the $5^{\prime}$ untranslated region (LiPA; Innogenetics, Ghent, Belgium).

\subsection{Statistical Analysis and Definitions}

Descriptive data with normal distribution are reported as mean \pm standard deviation (SD) or as percentage otherwise as median (range). The independent Student's $t$-test and Mann-Whitney U test were used to assess differences between groups in normal distributed and non-normal distributed variables, respectively. Chi-square test was used for categorical variables between the 2 groups. Two-tailed $p$ value $<0.05$ was considered as statistically significant.

To clarify the impact of antiviral regimen on tertiary prevention of HCC recurrence, HCC recurrence rate was calculated according to different time frames: from the end of hepatoma treatment to initiation of HCV treatment (Frame I), the period of HCV treatment (Frame II), and from end of HCV treatment (EOT) to two years post-EOT (Frame III). The corresponding time frames for untreated patients (Control group) were: (Frame I): from end of hepatoma treatment to six months post hepatoma treatment; (Frame II): 6-12 months after the end of hepatoma treatment and (Frame III): 12-36 months after the end of hepatoma treatment, as seen in Figure 3. Disease-free interval (DFI) was defined as the interval between the start of HCV treatment and the time of HCC recurrence or last follow-up. The Kaplan-Meier method and Log-Rank test were applied to estimate the difference of recurrence rate between the Peg-IFN/RBV and DAA arms. The Cox regression model was used to determine the associations of the predictive factors to clinical outcomes. Propensity score matching with a 1:1 ratio was applied to adjust for the differences between the DAA and Peg-IFN/RBV arms, including HCC staging, HCC treatment modality, age, and fibrosis status at time of antiviral treatment initiation. Statistical analyses were performed using SAS version 9.4 and SPSS software, version 20.0 (SPSS, Inc., Chicago, IL, USA). 


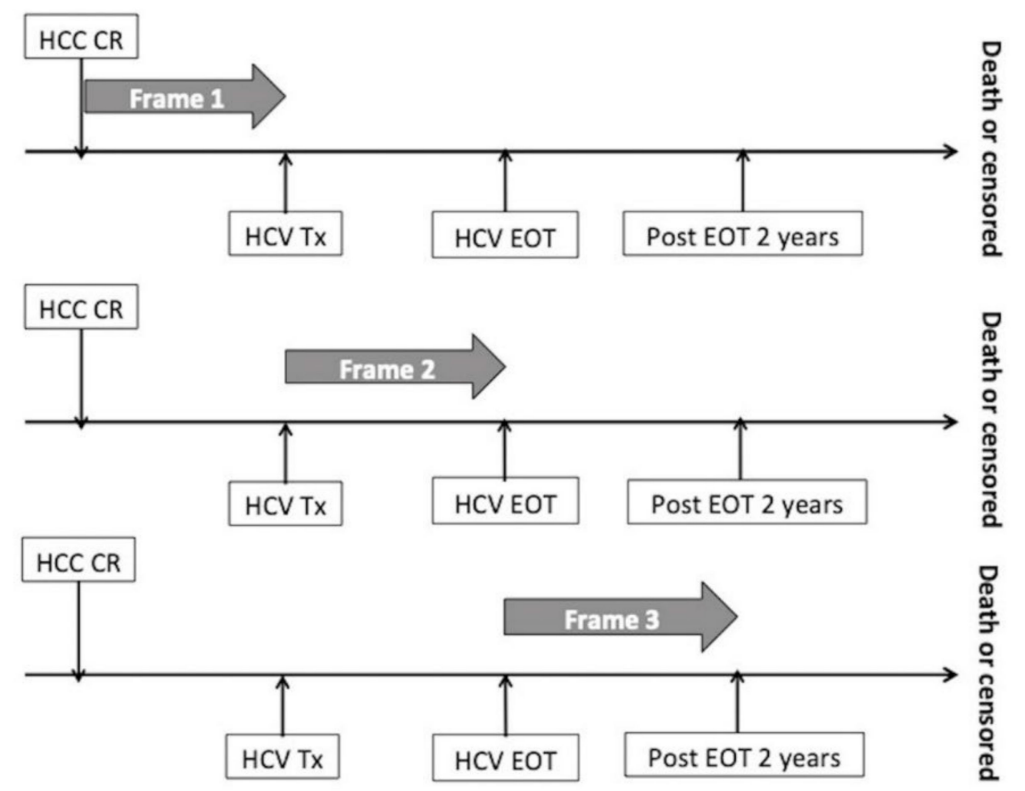

Figure 3. Illustration of different time frames. Abbreviations: $\mathrm{CR}-$ complete response; EOT—end of HCV treatment; HCC - hepatocellular carcinoma; HCV—hepatitis C virus infection; Tx - treatment.

\section{Conclusions}

Both IFN and DAA had different durabilities in their tertiary prevention effect for HCC recurrence in postcurative HCC treatment of CHC-HCC patients. The Peg-IFN/RBV regimen has a much better and more durable preventive effect than the temporary effect of DAA therapy. Preantiviral therapy ALBI grade is the only predictor for postantiviral therapy HCC recurrence. Close surveillance for detection of HCC recurrence is mandatory in curative HCC patients choosing DAA as a tertiary prevention regimen.

Supplementary Materials: The following are available online at http://www.mdpi.com/2072-6694/12/1/23/s1, Figure S1: Kaplan-Meier curves showing cumulative recurrence rate at different time frames. Figure S2: Kaplan-Meier curves showing cumulative recurrence rate. Supplementary Table S1: Characteristics comparison among untreated, Peg-IFN/RBV and DAA arms before PSM. Supplementary Table S2: HCC recurrence pattern comparison between Peg-IFN/RBV and DAA arms before PSM. Supplementary Table S3: Predictors for HCC recurrence in Peg-IFN/RBV treated and DAA treated patients before PSM by Cox regression analysis. Supplementary Table S4: Characteristics comparison at time of antiviral therapy between HCC recurrent and non-recurrent patients.

Author Contributions: Concept and design: W.-J.J., C.-Y.L., H.-I.Y., S.-M.L., I.-S.S.; Data acquisition: W.T., W.-T.C., Y.-C.H., C.-H.H., C.-C.L.; Manuscript writing: W.T., Statistical analysis: W.T., W.-J.J., H.-I.Y. Manuscript supervision: W.-J.J., C.-Y.L. All authors have read and agreed to the published version of the manuscript.

Funding: This study was supported by grants from Chang Gung Medical Research Fund (CMRPG3H0561, CORPG3H0671), National Science Council, Taiwan (MOST1072314B182A142).

Acknowledgments: The authors thank Ms. Pei-Jyue Lin for HCV dataset maintenance and update.

Conflicts of Interest: The authors have no financial and personal relationships with other people or organizations that could inappropriately influence (bias) their work.

\section{References}

1. Akinyemiju, T.; Abera, S.; Ahmed, M.; Alam, N.; Alemayohu, M.A.; Allen, C.; Al-Raddadi, R.; Alvis-Guzman, N.; Amoako, Y.; Artaman, A.; et al. The Burden of Primary Liver Cancer and Underlying Etiologies From 1990 to 2015 at the Global, Regional, and National Level. JAMA Oncol. 2017, 3, 1683.

2. Walter, S.R.; Thein, H.H.; Gidding, H.F.; Amin, J.; Law, M.G.; George, J.; Dore, G.J. Risk factors for hepatocellular carcinoma in a cohort infected with hepatitis B or C. J. Gastroenterol. Hepatol. 2011, 26, 1757-1764. [CrossRef] 
3. Morgan, R.L.; Baack, B.; Smith, B.D.; Yartel, A.; Pitasi, M.; Falck-Ytter, Y. Eradication of hepatitis C virus infection and the development of hepatocellular carcinoma: A meta-analysis of observational studies. Ann. Intern. Med. 2013, 158, 329-337. [CrossRef]

4. Manthravadi, S.; Paleti, S.; Pandya, P. Impact of sustained viral response postcurative therapy of hepatitis C-related hepatocellular carcinoma: A systematic review and meta-analysis. Int. J. Cancer 2017, 140, 1042-1049. [CrossRef]

5. Shinkawa, H.; Hasegawa, K.; Arita, J.; Akamatsu, N.; Kaneko, J.; Sakamoto, Y.; Kokudo, N. Impact of Sustained Virological Response to Interferon Therapy on Recurrence of Hepatitis C Virus-Related Hepatocellular Carcinoma. Ann. Surg. Oncol. 2017, 24, 3196-3202. [CrossRef]

6. Teng, W.; Hsieh, Y.C.; Lui, K.W.; Chen, W.T.; Hung, C.F.; Huang, C.H.; Chen, Y.C.; Jeng, W.J.; Lin, C.C.; Lin, C.Y.; et al. Eradication of hepatitis $C$ virus profoundly prolongs survival in hepatocellular carcinoma patients receiving transarterial chemoembolization. J. Viral Hepat. 2017, 24, 1160-1167. [CrossRef]

7. Foruny, J.R.; Blazquez, J.; Moreno, A.; Barcena, R.; Gil-Grande, L.; Quereda, C.; Pérez-Elías, M.J.; Moreno, J.; Sánchez, J.; Muriel, A.; et al. Safe use of pegylated interferon/ribavirin in hepatitis $C$ virus cirrhotic patients with hypersplenism after partial splenic embolization. Eur. J. Gastroenterol. Hepatol. 2005, 17, 1157-1164. [CrossRef] [PubMed]

8. European Association for the Study of the Liver. EASL Recommendations on Treatment of Hepatitis C 2018. J. Hepatol. 2018, 69, 461-511. [CrossRef] [PubMed]

9. Panel A-IHG. Hepatitis C Guidance 2018 Update: AASLD-IDSA Recommendations for Testing, Managing, and Treating Hepatitis C Virus Infection. Clin. Infect. Dis. 2018, 67, 1477-1492. [CrossRef] [PubMed]

10. Waziry, R.; Hajarizadeh, B.; Grebely, J.; Amin, J.; Law, M.; Danta, M.; George, J.; Dore, G.J. Hepatocellular carcinoma risk following direct-acting antiviral HCV therapy: A systematic review, meta-analyses, and meta-regression. J. Hepatol. 2017, 67, 1204-1212. [CrossRef]

11. Reig, M.; Marino, Z.; Perello, C.; Inarrairaegui, M.; Ribeiro, A.; Lens, S.; Díaz, A.; Vilana, R.; Darnell, A.; Varela, M.; et al. Unexpected high rate of early tumor recurrence in patients with HCV-related HCC undergoing interferon-free therapy. J. Hepatol. 2016, 65, 719-726. [CrossRef] [PubMed]

12. Conti, F.; Buonfiglioli, F.; Scuteri, A.; Crespi, C.; Bolondi, L.; Caraceni, P.; Foschi, F.G.; Lenzi, M.; Mazzella, G.; Verucchi, G.; et al. Early occurrence and recurrence of hepatocellular carcinoma in HCV-related cirrhosis treated with direct-acting antivirals. J. Hepatol. 2016, 65, 727-733. [CrossRef] [PubMed]

13. El Kassas, M.; Funk, A.L.; Salaheldin, M.; Shimakawa, Y.; Eltabbakh, M.; Jean, K.; El Tahan, A.; Sweedy, A.T.; Afify, S.; Youssef, N.F.; et al. Increased recurrence rates of hepatocellular carcinoma after DAA therapy in a hepatitis C-infected Egyptian cohort: A comparative analysis. J. Viral Hepat. 2018, 25, 623-630. [CrossRef] [PubMed]

14. Warzyszynska, K.; Jonas, M.; Wasiak, D.; Kosieradzki, M.; Malkowski, P. Accelerated hepatocellular carcinoma recurrence rate after postoperative direct-acting antivirals treatment-Preliminary report. Clin. Exp. Hepatol. 2017, 3, 194-197. [CrossRef] [PubMed]

15. The, A.N.R.S. Lack of evidence of an effect of direct-acting antivirals on the recurrence of hepatocellular carcinoma: Data from three ANRS cohorts. J. Hepatol. 2016, 65, 734-740.

16. Cabibbo, G.; Petta, S.; Calvaruso, V.; Cacciola, I.; Cannavo, M.R.; Madonia, S.; Distefano, M.; Larocca, L.; Prestileo, T.; Tinè, F.; et al. Is early recurrence of hepatocellular carcinoma in HCV cirrhotic patients affected by treatment with direct-acting antivirals? A prospective multicentre study. Aliment. Pharmacol. Ther. 2017, 46, 688-695. [CrossRef]

17. Kolly, P.; Waidmann, O.; Vermehren, J.; Moreno, C.; Vögeli, I.; Berg, T.; Semela, D.; Zeuzem, S.; Dufour, J.F. Hepatocellular carcinoma recurrence after direct antiviral agent treatment: A European multicentre study. J. Hepatol. 2017, 67, 876-878. [CrossRef]

18. Virlogeux, V.; Pradat, P.; Hartig-Lavie, K.; Bailly, F.; Maynard, M.; Ouziel, G.; Poinsot, D.; Lebossé, F.; Ecochard, M.; Radenne, S.; et al. Direct-acting antiviral therapy decreases hepatocellular carcinoma recurrence rate in cirrhotic patients with chronic hepatitis C. Liver Int. 2017, 37, 1122-1127. [CrossRef]

19. Zavaglia, C.; Okolicsanyi, S.; Cesarini, L.; Mazzarelli, C.; Pontecorvi, V.; Ciaccio, A.; Strazzabosco, M.; Belli, L.S. Is the risk of neoplastic recurrence increased after prescribing direct-acting antivirals for HCV patients whose HCC was previously cured? J. Hepatol. 2017, 66, 236-237. [CrossRef] 
20. Ikeda, K.; Kawamura, Y.; Kobayashi, M.; Kominami, Y.; Fujiyama, S.; Sezaki, H.; Hosaka, T.; Akuta, N.; Saitoh, S.; Suzuki, F.; et al. Direct-Acting Antivirals Decreased Tumor Recurrence After Initial Treatment of Hepatitis C Virus-Related Hepatocellular Carcinoma. Dig. Dis. Sci. 2017, 62, 2932-2942. [CrossRef]

21. Saraiya, N.; Yopp, A.C.; Rich, N.E.; Odewole, M.; Parikh, N.D.; Singal, A.G. Systematic review with meta-analysis: Recurrence of hepatocellular carcinoma following direct-acting antiviral therapy. Aliment. Pharmacol. Ther. 2018, 48, 127-137. [CrossRef] [PubMed]

22. Singh, S.; Nautiyal, A.; Loke, Y.K. Oral direct-acting antivirals and the incidence or recurrence of hepatocellular carcinoma: A systematic review and meta-analysis. Frontline Gastroenterol. 2018, 9, 262-270. [CrossRef] [PubMed]

23. Huang, A.C.; Mehta, N.; Dodge, J.L.; Yao, F.Y.; Terrault, N.A. Direct-acting antivirals do not increase the risk of hepatocellular carcinoma recurrence after local-regional therapy or liver transplant waitlist dropout. Hepatology 2018, 68, 449-461. [CrossRef] [PubMed]

24. Singal, A.G.; Rich, N.E.; Mehta, N.; Branch, A.; Pillai, A.; Hoteit, M.; Volk, M.; Odewole, M.; Scaglione, S.; Guy, J.; et al. Direct-Acting Antiviral Therapy Not Associated with Recurrence of Hepatocellular Carcinoma in a Multicenter North American Cohort Study. Gastroenterology 2019, 156, 1683-1692. [CrossRef]

25. Cabibbo, G.; Celsa, C.; Calvaruso, V.; Petta, S.; Cacciola, I.; Cannavò, M.R.; Madonia, S.; Rossi, M.; Magro, B.; Rini, F.; et al. Direct acting antivirals after successful treatment of early hepatocellular carcinoma improve survival in HCV-cirrhotic patients. J. Hepatol. 2019, 71, 265-273. [CrossRef]

26. Minami, T.; Tateishi, R.; Nakagomi, R.; Fujiwara, N.; Sato, M.; Enooku, K.; Nakagawa, H.; Asaoka, Y.; Kondo, Y.; Shiina, S.; et al. The impact of direct-acting antivirals on early tumor recurrence after radiofrequency ablation in hepatitis C-related hepatocellular carcinoma. J. Hepatol. 2016, 65, 1272-1273. [CrossRef]

27. Nishibatake Kinoshita, M.; Minami, T.; Tateishi, R.; Wake, T.; Nakagomi, R.; Fujiwara, N.; Sato, M.; Uchino, K.; Enooku, K.; Nakagawa, H.; et al. Impact of direct-acting antivirals on early recurrence of HCV-related HCC: Comparison with interferon-based therapy. J. Hepatol. 2019, 70, 78-86. [CrossRef]

28. Nagata, H.; Nakagawa, M.; Asahina, Y.; Sato, A.; Asano, Y.; Tsunoda, T.; Miyoshi, M.; Kaneko, S.; Otani, S.; Kawai-Kitahata, F.; et al. Effect of interferon-based and -free therapy on early occurrence and recurrence of hepatocellular carcinoma in chronic hepatitis C. J. Hepatol. 2017, 67, 933-939. [CrossRef]

29. Nagaoki, Y.; Imamura, M.; Nisihda, Y.; Daijo, K.; Teraoka, Y.; Honda, F.; Nakamura, Y.; Morio, K.; Fujino, H.; Nakahara, T.; et al. The impact of interferon-free direct-acting antivirals on clinical outcome after curative treatment for hepatitis C virus-associated hepatocellular carcinoma; comparison with interferon-based therapy. J. Med. Virol. 2019, 91, 650-658. [CrossRef]

30. Petta, S.; Cabibbo, G.; Barbara, M.; Attardo, S.; Bucci, L.; Farinati, F.; Giannini, E.G.; Tovoli, F.; Ciccarese, F.; Rapaccini, G.L.; et al. Hepatocellular carcinoma recurrence in patients with curative resection or ablation: Impact of HCV eradication does not depend on the use of interferon. Aliment. Pharmacol. Ther. 2017, 45, 160-168. [CrossRef]

31. Ioannou, G.N.; Feld, J.J. What Are the Benefits of a Sustained Virologic Response to Direct-Acting Antiviral Therapy for Hepatitis C Virus Infection? Gastroenterology 2019, 156, 446-460. [CrossRef] [PubMed]

32. Yu, M.L.; Lin, S.M.; Chuang, W.L.; Dai, C.Y.; Wang, J.H.; Lu, S.N.; Sheen, I.S.; Chang, W.Y.; Lee, C.M.; Liaw, Y.F. A sustained virological response to interferon or interferon/ribavirin reduces hepatocellular carcinoma and improves survival in chronic hepatitis C: A nationwide, multicentre study in Taiwan. Antivir. Ther. 2006, 11, 985-994. [PubMed]

33. Hsu, H.C.; Chou, W.C.; Shen, W.C.; Wu, C.E.; Chen, J.S.; Liau, C.T.; Lin, Y.C.; Yang, T.S. Efficacy of postoperative oxaliplatin-or irinotecan-based chemotherapy after curative resection of synchronous liver metastases from colorectal cancer. Anticancer Res. 2013, 33, 3317-3325. [PubMed]

34. Torres, H.A.; Vauthey, J.N.; Economides, M.P.; Mahale, P.; Kaseb, A. Hepatocellular carcinoma recurrence after treatment with direct-acting antivirals: First, do no harm by withdrawing treatment. J. Hepatol. 2016, 65, 862-864. [CrossRef] [PubMed]

35. Nahon, P.; Layese, R.; Bourcier, V.; Cagnot, C.; Marcellin, P.; Guyader, D.; Pol, S.; Larrey, D.; De Lédinghen, V.; Ouzan, D.; et al. Incidence of Hepatocellular Carcinoma After Direct Antiviral Therapy for HCV in Patients with Cirrhosis Included in Surveillance Programs. Gastroenterology 2018, 155, 1436-1450. [CrossRef] 
36. Guarino, M.; Vigano, L.; Ponziani, F.R.; Giannini, E.G.; Lai, Q.; Morisco, F.; Vitale, A.; Russo, F.P.; Cillo, U.; Burra, P.; et al. Recurrence of hepatocellular carcinoma after direct acting antiviral treatment for hepatitis $C$ virus infection: Literature review and risk analysis. Dig. Liver Dis. 2018, 50, 1105-1114. [CrossRef]

37. van der Meer, A.J.; Veldt, B.J.; Feld, J.J.; Wedemeyer, H.; Dufour, J.F.; Lammert, F.; Duarte-Rojo, A.; Heathcote, E.J.; Manns, M.P.; Kuske, L.; et al. Association between sustained virological response and all-cause mortality among patients with chronic hepatitis $C$ and advanced hepatic fibrosis. JAMA 2012, 308, 2584-2593. [CrossRef]

38. Toyoda, H.; Kumada, T.; Tada, T. Changes in patient backgrounds may increase the incidence of HCC after SVR in the era of IFN-free therapy for HCV. Hepatology 2016, 64, 1818-1819. [CrossRef]

39. Llovet, J.M.; Di Bisceglie, A.M.; Bruix, J.; Kramer, B.S.; Lencioni, R.; Zhu, A.X.; Sherman, M.; Schwartz, M.; Lotze, M.; Talwalkar, J.; et al. Design and endpoints of clinical trials in hepatocellular carcinoma. J. Natl. Cancer Inst. 2008, 100, 698-711. [CrossRef]

40. Jeong, S.; Aikata, H.; Katamura, Y.; Azakami, T.; Kawaoka, T.; Saneto, H.; Uka, K.; Mori, N.; Takaki, S.; Kodama, H.; et al. Low-dose intermittent interferon-alpha therapy for HCV-related liver cirrhosis after curative treatment of hepatocellular carcinoma. World J. Gastroenterol. 2007, 13, 5188-5195. [CrossRef]

41. Kanogawa, N.; Ogasawara, S.; Chiba, T.; Saito, T.; Motoyama, T.; Suzuki, E.; Ooka, Y.; Tawada, A.; Kanda, T.; Mikami, S.; et al. Sustained virologic response achieved after curative treatment of hepatitis $C$ virus-related hepatocellular carcinoma as an independent prognostic factor. J. Gastroenterol. Hepatol. 2015, 30, 1197-1204. [CrossRef] [PubMed]

42. Kao, W.Y.; Su, C.W.; Chiou, Y.Y.; Chiu, N.C.; Liu, C.A.; Fang, K.C.; Huo, T.I.; Huang, Y.H.; Chang, C.C.; Hou, M.C.; et al. Hepatocellular Carcinoma: Nomograms Based on the Albumin-Bilirubin Grade to Assess the Outcomes of Radiofrequency Ablation. Radiology 2017, 285, 670-680. [CrossRef] [PubMed]

43. Hiraoka, A.; Kumada, T.; Kudo, M.; Hirooka, M.; Tsuji, K.; Itobayashi, E.; Kariyama, K.; Ishikawa, T.; Tajiri, K.; Ochi, H.; et al. Albumin-Bilirubin (ALBI) Grade as Part of the Evidence-Based Clinical Practice Guideline for HCC of the Japan Society of Hepatology: A Comparison with the Liver Damage and Child-Pugh Classifications. Liver Cancer 2017, 6, 204-215. [CrossRef]

44. Pinato, D.J.; Sharma, R.; Allara, E.; Yen, C.; Arizumi, T.; Kubota, K.; Bettinger, D.; Jang, J.W.; Smirne, C.; Kim, Y.W.; et al. The ALBI grade provides objective hepatic reserve estimation across each BCLC stage of hepatocellular carcinoma. J. Hepatol. 2017, 66, 338-346. [CrossRef] [PubMed]

45. Chan, A.W.; Chong, C.C.; Mo, F.K.; Wong, J.; Yeo, W.; Johnson, P.J.; Yu, S.; Lai, P.B.; Chan, A.T.; To, K.F.; et al. Applicability of albumin-bilirubin-based Japan integrated staging score in hepatitis B-associated hepatocellular carcinoma. J. Gastroenterol. Hepatol. 2016, 31, 1766-1772. [CrossRef] [PubMed]

46. Wang, Y.Y.; Zhong, J.H.; Su, Z.Y.; Huang, J.F.; Lu, S.D.; Xiang, B.D.; Ma, L.; Qi, L.N.; Ou, B.N.; Li, L.Q. Albumin-bilirubin versus Child-Pugh score as a predictor of outcome after liver resection for hepatocellular carcinoma. Br. J. Surg. 2016, 103, 725-734. [CrossRef] [PubMed]

47. Toyoda, H.; Lai, P.B.; O’Beirne, J.; Chong, C.C.; Berhane, S.; Reeves, H.; Manas, D.; Fox, R.P.; Yeo, W.; Mo, F.; et al. Long-term impact of liver function on curative therapy for hepatocellular carcinoma: Application of the ALBI grade. Br. J. Cancer 2016, 114, 744-750. [CrossRef] [PubMed]

48. Di Marco, V.; Calvaruso, V.; Ferraro, D.; Bavetta, M.G.; Cabibbo, G.; Conte, E.; Cammà, C.; Grimaudo, S.; Pipitone, R.M.; Simone, F.; et al. Effects of Eradicating Hepatitis C Virus Infection in Patients with Cirrhosis Differ with Stage of Portal Hypertension. Gastroenterology 2016, 151, 130-139. [CrossRef]

49. Hamdane, N.; Jühling, F.; Crouchet, E.; El Saghire, H.; Thumann, C.; Oudot, M.A.; Bandiera, S.; Saviano, A.; Ponsolles, C.; Suarez, A.A.R.; et al. HCV-Induced Epigenetic Changes Associated with Liver Cancer Risk Persist After Sustained Virologic Response. Gastroenterology 2019, 156, 2313-2329.e2317. [CrossRef]

50. Torzilli, G.; Minagawa, M.; Takayama, T.; Inoue, K.; Hui, A.M.; Kubota, K.; Ohtomo, K.; Makuuchi, M. Accurate preoperative evaluation of liver mass lesions without fine-needle biopsy. Hepatology 1999, 30, 889-893. [CrossRef]

51. European Association for the Study of the Liver. Electronic address eee, European Association for the Study of the L. EASL Clinical Practice Guidelines: Management of hepatocellular carcinoma. J. Hepatol. 2018, 69, 182-236. [CrossRef] [PubMed] 
52. Lencioni, R.; Llovet, J.M. Modified RECIST (mRECIST) assessment for hepatocellular carcinoma. Semin. Liver Dis. 2010, 30, 52-60. [CrossRef] [PubMed]

53. European Association for the Study of the Liver. EASL Recommendations on Treatment of Hepatitis C 2016. J. Hepatol. 2017, 66, 153-194. [CrossRef] [PubMed]

(C) 2019 by the authors. Licensee MDPI, Basel, Switzerland. This article is an open access article distributed under the terms and conditions of the Creative Commons Attribution (CC BY) license (http://creativecommons.org/licenses/by/4.0/). 